\title{
O PAPEL DO HUMOR NO CINEMA DO SUBURBANISMO FANTÁSTICO
}

\section{THE ROLE OF HUMOR IN THE SUBURBAN FANTASTIC CINEMA}

\author{
India Mara MARTINS* \\ Pedro Artur Baptista LAURIA**
}

\begin{abstract}
Resumo: O subúrbio estadunidense é marcado por um recorte social bastante específico: uma classe média branca, arraigada em um discurso meritocrata e vinculada ao "Sonho Americano". Sua imagem idílica foi consolidada desde os anos 1950 pelas sitcoms de subúrbio, mas também passou a ser contraposta pelo suburbanismo gótico - subgênero literário que também encontrou ambiente fértil no audiovisual. Nestes subgêneros o humor se apresenta de forma dicotômica e contraditória, e pode ser resumido nas seguintes máximas: rir conosco ou rir de nós. Nosso interesse neste artigo reside na investigação do uso do humor em um terceiro subgênero, este muito mais recente: o suburbanismo fantástico. Esse subgênero é definido por McFadzean como um conjunto de filmes hollywoodianos que começaram a aparecer nos anos 1980, em que crianças e adolescentes que vivem no subúrbio são chamados para confrontar uma força fantástica e disruptiva, tais quais E.T. - O Extraterrestre, Os Goonies e De Volta Para o Futuro. Este artigo, então, se aprofunda no papel mercadológico, narrativo e moral do humor nessas narrativas, considerando tanto o seu público alvo como sua natureza sintática explicitamente reacionária, e que, por isso, contrapõe a natureza subversiva tanto dos gêneros de comédia quanto de fantasia, que se fundamentam no confronto, respectivamente, das expectativas e das regras do real.
\end{abstract}

Palavras-Chave: Suburbanismo fantástico. Subúrbio. Humor. Gênero. Classe média.

\begin{abstract}
The American suburb is defined by a very specific social profile: a white middle class, bearer of a meritocratic speech and linked to the "American Dream". The American suburb idyllic image has been consolidated since the 1950s by Suburban Sitcoms, but it has also been contested by the Suburban Gothic - a literary subgenre that also found a fertile environment in audiovisual. In these subgenres, humor is presented in a dichotomous and contradictory way, which can be summarized by the following maxims: laugh with or at us. This paper aims to investigate the use of humor in a third subgenre, this one much more recent: the Suburban Fantastic Cinema. It is defined by McFadzean as a set of Hollywood films that began appearing in the 1980s, in which children and adolescents living in the suburbs are called upon to confront a fantastic and disruptive force, such as ET - The Extraterrestrial, The Goonies and Back to the Future. This paper analyzes the marketing, narrative and moral role of humor in these narratives, considering both its target audience and its explicitly reactionary syntactic nature, which, therefore, opposes the subversive nature of both Comedy and Fantasy - genres that are based on the confrontation of expectations and of the rules of reality.
\end{abstract}

Keywords: Suburban fantastic cinema. Suburbs. Humor. Genre. Middle class.

\footnotetext{
* Doutora em Design pela PUC-Rio. Professora Associada do PPGCine, da Universidade Federal Fluminense. Email: indiamartins@id.uff.br. ORCID: http://orcid.org/0000-0002-9202-4645

** Doutorando em Cinema e Audiovisual pela UFF. Mestre em Comunicação Social pela UFRJ. E-mail: pedrolauria@gmail.com. ORCID: https://orcid.org/0000-0002-4394-4584
} 


\section{Introdução: o subúrbio estadunidense e suas representações}

O que pensamos quando ouvimos a palavra subúrbio? No Brasil, muitos pensarão nos subúrbios cariocas eternizados nos filmes de Nelson Pereira dos Santos Rio, 40 Graus (1955) e Rio, Zona Norte (1957), ou em novelas como Avenida Brasil (João Emanuel Carneiro, Globo, 2012) e Bom Sucesso (Rosane Svartman e Paulo Halm, Globo, 2019-20). Outros poderão pensar no idílico subúrbio estadunidense, marcado por casas iguais, cercas brancas, jardins bem cuidados e habitadas por famílias nucleares brancas de classe média. Essa imagem, é claro, foi criada justamente a partir do consumo repetitivo de representações em obras audiovisuais que se localizam nesse tipo de urbanização. A distinção tão grande entre os subúrbios brasileiro e estadunidense advém do próprio termo "subúrbio", que apenas significa "às margens da cidade" e não designa nenhum tipo de urbanização, arquitetura ou demografia específica.

No entanto, a maior parte dos subúrbios ${ }^{1}$ estadunidenses corroboram de algumas características específicas. A primeira e mais óbvia é que se o subúrbio se constrói ao redor da cidade, logo, ele vem depois dela, sendo mais novo do que ela. Essa característica é importantíssima para compreender a dicotomia entre subúrbio e cidade que será criada a partir das expansões suburbanas nos Estados Unidos, na década de 1950. A segunda característica comum é de que ele não é a cidade. Logo, por definição, ele apresentará atributos diferentes da cidade que rodeia. Normalmente, terão menos equipamentos urbanos, menor densidade demográfica, e menos problemas urbanos, como violência, trânsito e poluição (BAUMGARTNER, 1988).

A terceira característica é de que, justamente pelo subúrbio não ser a cidade, ele passa a ser dependente da mesma. Seja por conta de empregos, serviços, acesso a equipamentos urbanos ou outras facilidades. Logo, quanto mais equipada for uma cidade, maior sua predisposição de ter uma suburbanização ao seu entorno. Essa realização, nos leva a mais um desdobramento categórico: isso significa que, entre o subúrbio e a cidade, há a necessidade de infraestrutura para movimentos pendulares: estradas, linhas de trem, metrô, etc. Quem mora no subúrbio e trabalha na cidade vai precisar se deslocar diariamente. Existe inclusive um verbo em inglês específico para definir esses deslocamentos rotineiros: commute [viajar diariamente entre a casa e o trabalho]. E se não existem serviços de transporte público que liguem ambos, o carro passa a ser exigência para esse deslocamento. Logo, nesses casos, os subúrbios reforçam suas características classistas que existem desde o seu fomento imobiliário na década de 1920

\footnotetext{
${ }^{1}$ Salvo acompanhado de ressalva, a partir de agora, toda vez que nos referirmos à subúrbio ou suburbano, estamos falando exclusivamente do subúrbio estadunidense.
} 
e 1940. Como bem resume Ávila (2004), os Estados Unidos vão ter uma divisão racial e econômica que pode ser resumida na analogia dos "subúrbios baunilhas e cidades chocolate".

A professora e pesquisadora Bernadette Hanlon reforça a tese de que o "sonho americano" se manifestaria de forma mais apurada em seus subúrbios, baseados na ideia de que ali seja uma terra de oportunidades, cobiçada pela sua origem como uma "utopia burguesa", antes apenas acessível para a elite. No início de seu livro Once the American dream (2009), ela traz uma citação do historiador James Adams no livro The Epic of America, responsável por cunhar o termo sonho americano. Ele o define como:

o sonho de uma terra que a vida deve ser melhor, mais rica e mais completa para todo mundo, com oportunidades para cada um de acordo com sua habilidade e conquistas... É... o sonho de uma ordem social em que cada homem e cada mulher sejam aptos para conseguir a máxima estatura que são inatamente capazes, e reconhecidos pelo que são, independentemente das circunstâncias de nascimento ou posição social. (Adams, $1931^{2}$ apud Hanlon, 2009, p 1. Tradução do autor P.L.) $)^{3}$.

Por isso, quando falamos dos subúrbios estadunidenses, estaremos falando em sonhos, utopias e padrões de vida almejados, independentes da condição financeira daquele território. Em uma analogia que talvez seja elucidativa para o leitor brasileiro, mudar-se para o subúrbio nos Estados Unidos opera de forma muito similar ao "sonho da casa própria" em nosso país. Ou seja, ter uma casa em um subúrbio passa a ser o desejo de grande parte de uma população metropolitana, seja motivado por ascensão de classe, fuga dos problemas urbanos ou por ser "o lugar ideal para se ter uma família”. Assim, o discurso pró-subúrbio trabalhará com a ideia de modernidade, frente à decadência e obsolescência das grandes cidades e centros industriais.

Como presumível, a dicotomia entre subúrbio e cidade não se restringe a discursos e a representações artísticas positivas do primeiro e negativas da segunda. Na literatura e no audiovisual, o subúrbio é representado de forma bastante distinta e, por vezes, contraditória. Para ilustrar esse contraste de retratos, a autora Bernice Murphy faz um didático sumário (Quadro 1) de oposições binárias de características antagônicas do subúrbio na literatura.

\footnotetext{
${ }^{2}$ ADAMS, James Truslow. The Epic of America. Boston: Little Brown, 1931.

${ }^{3}$ No original: "[The American Dream is] that dream of a land in which life should be better and richer and fuller for everyone, with opportunity for each according to ability or achievement... It is... a dream of social order in which each man and each woman shall be able to attain to the fullest stature of which they are innately capable, and be recognized by others for what they are, regardless of the fortuitous circumstances of birth or position"
} 
Quadro 1 - Oposição entre o sonho e o pesadelo suburbano

\begin{tabular}{|c|c|}
\hline SONHO SUBURBANO & PESADELO SUBURBANO \\
\hline Aprazível & Assombrado \\
\hline A oportunidade da casa própria & A possibilidade de se endividar \\
\hline Bons vizinhos & Vizinhos que escondem alguma coisa \\
\hline Uma ambientação utópica para uma vida melhor & Um lugar de confinamento e tristeza \\
\hline Um lugar seguro para crianças & Um local de caça para pedófilos \\
\hline Um lugar para recomeçar & Um lugar preso ao passado \\
\hline Um refúgio bucólico da poluição da cidade & Um destruidor do campo e devorador de \\
recursos naturais
\end{tabular}

Fonte: Murphy (2009, p.4, tradução do autor P.L.)

\section{(Sub)gêneros passados no Subúrbio}

Essas representações díspares do subúrbio, mais do que diferentes perspectivas desse modelo de urbanização, são instrumentais para a produção de múltiplos (sub)gêneros passados nessa ambientação. Afinal, é dessa representação que advém elementos semânticos e sintáticos vinculados a diferentes (sub)gêneros (sejam literários, audiovisuais, etc). Por exemplo, porões desorganizados e sujos são elementos recorrentes em filmes de horror ${ }^{4}$ enquanto o retrato do subúrbio como "um lugar para recomeçar" é parte da trama de múltiplos dramas e romances. Nos próximos parágrafos nos concentraremos em três diferentes subgêneros audiovisuais passados no subúrbio, que se fundamentam em retratos bastante variados desse modelo de urbanização e de seus moradores.

Comecemos com as sitcoms de subúrbio, marcadas pela produção seriada estadunidense da década de 1950, sempre com modelos de família idealizados e conflitos facilmente solucionáveis. Exemplos delas são As Aventuras de Ozzie e Harriet (The Adventures of Ozzie

\footnotetext{
${ }^{4}$ Como se trata de um trabalho muito vinculado aos estudos genéricos, o itálico será utilizado para falar de (sub)gêneros (sejam eles audiovisuais ou literários) com intuito de destáca-los e facilitar a compreensão do leitor.
} 
and Harriet, Ozzie Nelson, ABC, 1952-1966), Papai Sabe Tudo (Father Knows Best, Ed James, CBS, 1954-1963) e Leave it To Beaver (Joe Connely e Bob Mosher, CBS, 1957-58; ABC 195863). Ella Taylor (1989, p.26) descreve tais famílias de sitcom como "sonhos liberaisconservadores de uma sociedade harmônica e sem conflitos sociais" onde a comédia ajudava a amenizar atribulações rotineiras e distrair os indivíduos de tensões da sociedade.

A cena apresentada na Figura 1 demonstra um pouco do caráter idílico e bucólico dos subúrbios das sitcom. As ruas tranquilas se mostram um local ideal para crianças.

Figura 1 - Cena de Leave it to Beaver

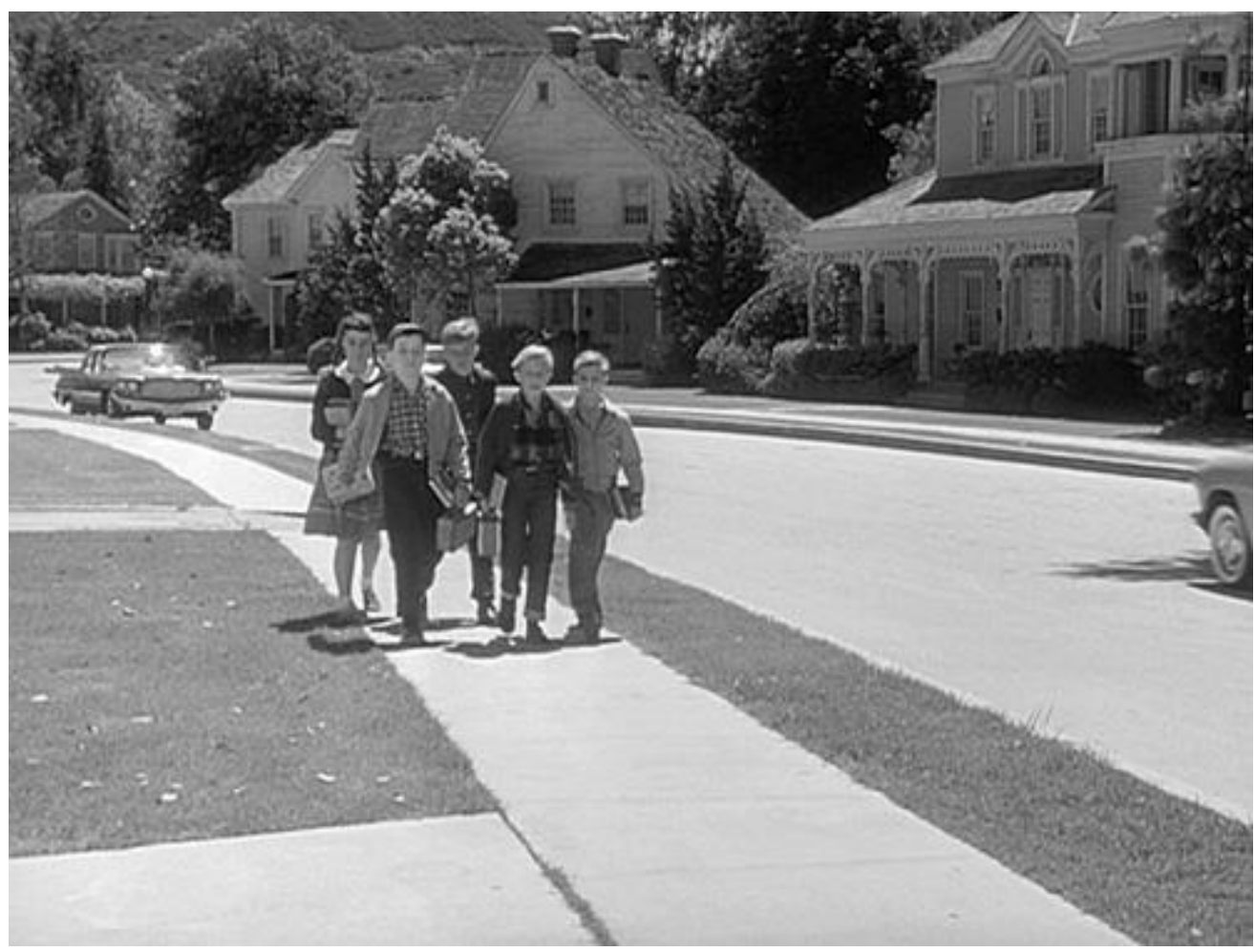

Fonte: Frame da série.

Elementos como cercas brancas, gramados bem aparados e fachadas bem cuidadas são responsáveis por um retrato bastante aprazível do subúrbio. Mais do que isso, eles reforçam as diferenças entre o subúrbio e os centros urbanos, explicitando as presumidas vantagens das áreas afastadas das metrópoles. Os jardins, árvores e proximidade com morros e bosques, representam um maior contato com a natureza. Já a falta de movimento de carros na rua, uma vez que se tratam de ambientações residenciais, reforçam a imagem de um ritmo menos apressado, onde crianças podem brincar nas ruas e andar pela vizinhança. Tais imagens e movimentos sublinham a imagem do subúrbio como um lugar ideal para construir sua família.

Assim, não surpreende que nessas sitcoms o humor esteja intimamente ligado à relação 
familiar. Ele aparece a partir de tiradas rápidas de seus personagens, ou a partir de problemas de comunicação entre os mesmos - nunca utilizado de forma a fazer suspeição do caráter ou criticar o estilo de vida suburbano. Os episódios duravam cerca de 20 minutos e não havia uma continuidade narrativa entre eles (COONTZ, 2000) o que exigia que os conflitos fossem apresentados e resolvidos nesse tempo. As piadas, geralmente acompanhadas das risadas de uma claque, serviam para demonstrar o desenrolar desses conflitos de forma leve e simpática sem maiores aprofundamentos ou desenvolvimentos emocionais.

Ao final de cada um dos episódios das sitcoms de subúrbio, a tendência era de que a ordem estivesse completamente reestabelecida. Mais do que isso, as coisas geralmente ficavam melhores do que antes. Os laços familiares se tornavam mais fortes, os personagens mais confiantes de suas capacidades e, claro, os casais mais apaixonados. O humor também era usado como elemento que atenuava o impacto dramático do arco narrativo de seus personagens e guiava o espectador tranquilamente por uma jornada com final feliz. A proposta era que o espectador se divertisse durante todo o episódio, e, ao seu fim, saísse com o sentimento de que eram aqueles valores e comportamentos ali representados que garantiriam a felicidade: a família, o romance heteronormativo, o trabalho duro e honesto (ROWLEY, 2015).

Trazendo uma representação completamente distinta está o suburbanismo gótico, já bastante consolidado dentro dos estudos genéricos, marcado por visões pessimistas, críticas e/ou cínicas do subúrbio e de seus moradores, rompendo com a imagem idealizada do "Sonho Americano". Inclusive é da professora Bernice Murphy que vem uma das definições mais concisas e didáticas do suburbanismo gótico: narrativas que "levantam suspeitas de que nas mais ordinárias vizinhanças, casas e famílias, não importando o quão calmas pareçam, estão a apenas um acontecimento de um incidente dramático (e geralmente sinistro)" (2009, p.3 $)^{5}$. São o caso de obras como A Primeira Noite de um Homem (The Graduate, Mike Nichols, 1967), Esposas em Conflitos (The Stepford Wives, Bryan Forbes, 1975), O Tiro que Não Saiu pela Culatra (Parenthood, Ron Howard, 1989), Beleza Americana (American Beauty, Sam Mendes, 1999) ou Pecados Íntimos (Little Children, Todd Field, 2006).

O suburbanismo gótico é um subgênero que demonstra algumas das crises da classe média suburbana. Uma discussão na mesa de jantar pode ser a gota d'água para que seus personagens cheguem ao seu limite. A Figura 2 apresenta uma cena de Beleza Americana em

\footnotetext{
${ }^{5}$ No original: "Suburban Gothic is a sub-genre concerned, first and foremost, with playing upon the lingering suspicion that even the most ordinary-looking neighbourhood, or house, or family, has something to hide, and that no matter how calm and settled a place looks, it is only ever a moment away from dramatic (and generally sinister) incident."
} 
que Lester Burnham, vivido por Kevin Spacey, joga um prato de aspargos na parede. O clima tenso, presente na cena, é intensificado pela paleta de cores escura e pela expressão de choque das personagens.

Figura 2 - Cena de Beleza Americana

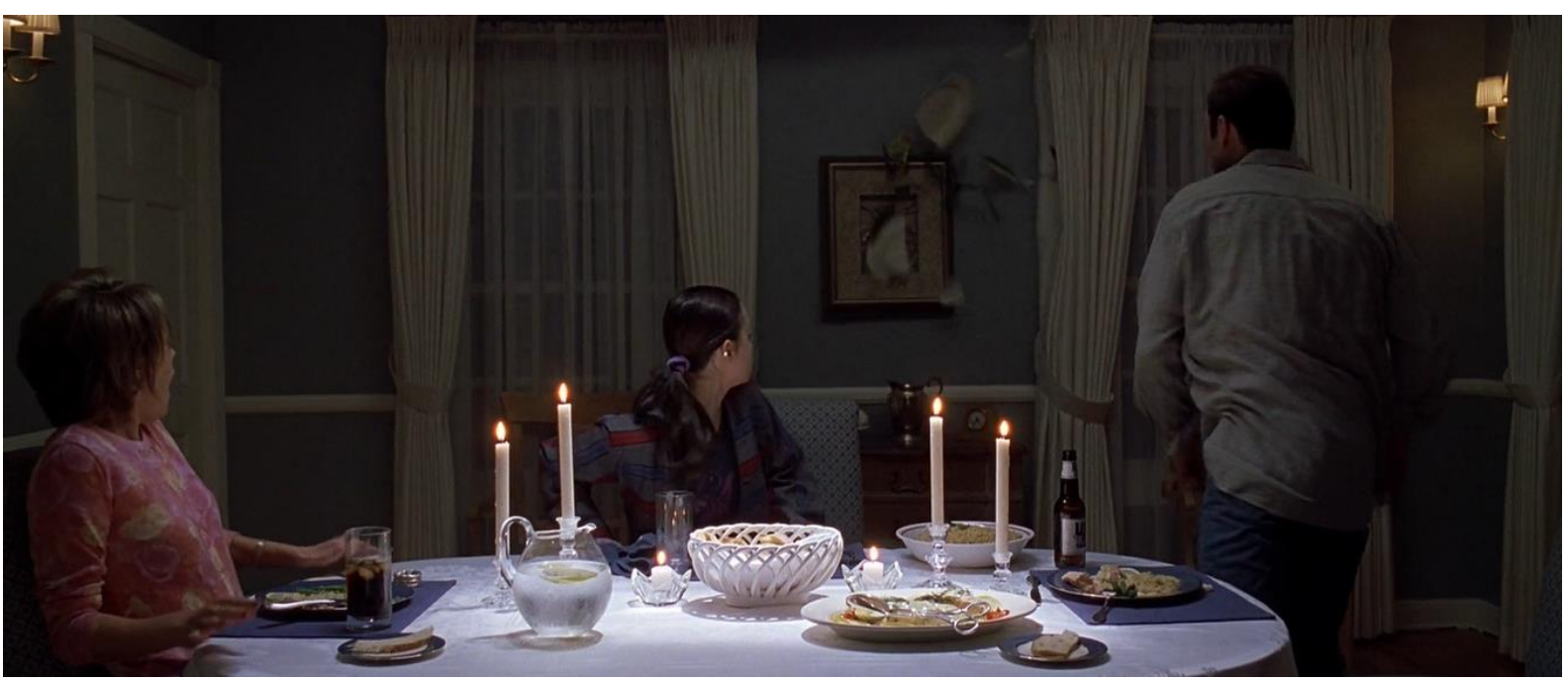

Fonte: Frame do filme.

Em Beleza Americana (imagem acima), um simples jantar a luz de velas é o cenário em que se deflagram as tensões de uma família "aparentemente comum". Na obra de Sam Mendes, somos apresentados a uma família profundamente rachada, mas que tenta manter uma imagem de sucesso para seus vizinhos e colegas. O slogan que estampa o pôster do filme, "Look Closer" (“Olhe mais de perto"), faz uma alusão à essência do suburbanismo gótico: ao olharmos para além do jardim de rosas vermelhas, descobriremos os segredos, medos e apreensões. A aparente perfeição de seus personagens, não sobrevive a uma observação mais minunciosa.

Catherine Jurca em The White Diaspora (2001) traz uma citação de Anna Karenina (TOLSTOY, 2007) para ilustrar esses tais dramas suburbanos presentes no suburbanismo gótico:

Todas as famílias felizes são iguais. As infelizes o são cada uma à sua maneira”. Como corpo de trabalho, as histórias suburbanas consideram que uma família triste é muito parecida com as outras, e não existe essa coisa de família feliz. Divórcio, abandono, adultério, ilegitimidade, violência doméstica, incesto, doenças mentais, suicídio, matricídio: o termo "disfuncional" é dificilmente adequado para se endereçar ao escopo das falhas perenes. (JURCA , 2001, p.167) (tradução do autor P.L.) ${ }^{6}$

\footnotetext{
${ }^{6}$ No original: “All happy families are all alike; every unhappy family is unhappy in its own way." As a body of work, the suburban novel asserts instead that one unhappy family is a lot like the next, and there is no such thing as a happy family. Divorce, desertion, adultery, illegitimacy, domestic violence, incest, mental illness, suicide, matricide: the term "dysfunctional" is hardly adequate to address the scope of its continuous failure.
} 
Este olhar irônico e ácido, que ressalta as idiossincrasias e hipocrisias de seus moradores, reforçando o quão distante estão da imagem idealizada que querem representar, é, sem dúvida, uma constante autocrítica e um olhar minucioso para o "eu" e o "nós". O humor, dessa forma, é utilizado de maneira a rir das idiossincrasias e hipocrisias da própria sociedade e, mais especificamente, da classe média suburbana. Isto pode se dar tanto a partir de cenas cômicas em dramas, como o personagem Lester Burnham experimentando maconha em Beleza Americana quanto como premissa de comédias. Este é o caso da espetacularização da vida ao ponto de virar um show de TV em O Show de Truman (Truman Show, Peter Wier, 1998), dos impulsos (assassinos) de pais hiper-protetores em Mamãe é de Morte (Serial Mom, John Water, 1994) e da desumanização e do preconceito com grupos sociais retratados como zumbis em Fido (Andrew Currie, 2006).

Nessas obras, o riso é claramente vinculado à identificação de determinados comportamentos criticáveis - sejam nossos, de membros de nossa família ou de vizinhos. Ou seja, os conflitos e problemas já são advindos daquela estrutura social, estando apenas inertes ou camuflados. Isto faz com que as sitcoms de subúrbio entrem em clara oposição com o suburbanismo gótico, também, no que diz respeito ao humor. Afinal, se o primeiro prega a ideia de rir junto à família suburbana, o segundo se consolida na ideia de se rir da família suburbana (e porque não, de nós mesmos).

No entanto é um terceiro subgênero, ainda pouquíssimo estudado, que talvez traga uma estrutura de humor ainda mais condizente com a perspectiva suburbana de uma classe média classista e exclusivista. É sobre ele que vamos nos debruçar nos próximos tópicos.

\section{Suburbanismo fantástico: rindo do Outro}

O Suburban Fantastic Cinema, aqui traduzido como suburbanismo fantástico, foi primeiramente proposto como subgênero cinematográfico por Angus McFadzean em artigo de 2017 e, posteriormente, em um livro de mesmo nome em 2019. Segundo o autor o subgênero seria definido por:

um conjunto de filmes Hollywoodianos que começaram a aparecer nos anos de 1980, onde crianças e adolescentes que vivem no subúrbio são chamados para confrontar uma força fantástica e disruptiva - fantasmas, aliens, vampiros, gremlins e robôs maldosos. São filmes que emergiram de obras focadas no público adulto, melodramas suburbanos, e filmes e programas de horror, fantasia e aventura, clássicos dos anos de 1950, e que passaram a ser sinônimo dos trabalhos de diretores como Steven Spielberg, Joe Dante, Robert Zemeckis e Chris Columbus. Comumente adereçados como filmes de crianças ou filmes "família", sendo parte-chaves da infância do fim 
da geração X (1965-1980) e de toda geração millenial (1981-1996). (McFADZEAN, 2019, p.1) (tradução do autor P.L.) ${ }^{7}$

Em seu livro o autor cita dezenas de obras produzidas a partir da década de 1980, influenciadas pelo sucesso de Poltergeist (Poltergeist, Toby Hopper, 1982) e E.T. - O Extraterrestre (E.T. - The Extraterrestrial, Steven Spielberg, 1982). Dentre eles estão clássicos que acabaram por ajudar a definir nossa concepção do cinema jovem Hollywoodiano da década como Gremlins (1984), Os Goonies (The Goonies, Richard Donner, 1985), De Volta para o Futuro (Back to the Future, Robert Zemeckis, 1985), A Hora do Espanto (Fright Night, Tom Holland, 1985), Deu a Louca nos Monstros (Monster Squad, Fred Dekker, 1987), Querida, Encolhi as Crianças (Honey, I Shrunk the Kids, Joe Johnston, 1989) e Esqueceram de Mim (Home Alone, Chris Columbus, 1990).

Segundo McFadzean (2019), o suburbanismo fantástico mesclaria os elementos semânticos do gênero de fantasia, ficção científica e/ou terror aos elementos semânticos do subúrbio estadunidense. Sintaticamente, o subgênero conta a história de maturação/amadurecimento do protagonista de forma sincronizada à resolução das consequências causadas pelos elementos fantásticos. Ou seja, para o que nos interessa neste artigo, falamos de um amadurecimento do "eu" a partir da resolução dos problemas trazidos pelo "outro" - tido como fantástico (ou extraordinário). Resolução esta quase sempre construída a partir de cenas que se utilizam de humor: sejam eles monstros como em Gremlins, extraterrestres como em E.T. - O Extraterrestre, bandidos como Os Goonies e Esqueceram de Mim, ou mesmo experimentos científicos como em De Volta para o Futuro e Querida, Encolhi as Crianças.

É importante ressaltar que o humor, tal qual pontua Bergson quando fala do riso (1993, p.20), se dá sempre a partir da perspectiva de um dado grupo social. A subjetividade atrelada ao gênero advém primordialmente do fato de que atribuir algo como cômico depende também de quem é seu espectador. Nesse momento, faz-se importante reforçar a ligação do subúrbio à um recorte bastante específico: uma classe média branca, heteronormativa e patriarcal. Então, se trabalharmos o humor no suburbanismo fantástico a partir de uma perspectiva freudiana do humor (SANTOS, 2012, p.28) em que ele advém de dar "pouca importância aos infortúnios (...)

\footnotetext{
${ }^{7}$ No original: “'Suburban fantastic cinema' is a name that designates a set of Hollywood movies that started to appear in the 1980s, in which pre-teen and teenage boys living within the suburbs are called upon to confront a disruptive fantastic force - ghosts, aliens, vampires, gremlins and malevolent robots. These films emerged out of adult-focused, suburban-set melodramas, children's fantasy stories, and old-fashioned sf, horror, fantasy and adventure films and television mainly of the 1950s, and became synonymous with the work of Steven Spielberg, Joe Dante, Robert Zemeckis and Chris Columbus. Typically marketed as children's films or 'family' films, they were key parts of the childhood of late-Generation Xer's and millennials."
} 
proporcionando a economia do sentimento" ele também está vinculado à própria subjetividade de tal classe social. Afinal, se tratam dos "infortúnios" aos quais ela consegue dar pouca importância, pois consegue se distanciar sentimentalmente.

Partindo desse eclarecimento, nos próximos tópicos iremos nos aprofundar em possíveis motivações e desdobramentos que nos auxiliem na compreensão do papel do humor dentro do subgênero, levando em consideração todos os valores atrelados ao subúrbio que vimos no início do trabalho.

\section{A importância mercadológica do humor}

O primeiro e mais evidente motivo do uso do humor no subgênero está ligado a demografia de seu público alvo. Isso pois o suburbanismo fantástico é um dos (sub)gêneros pelo qual Hollywood pode falar mais diretamente com sua audiência chave: famílias de classe média suburbana. Assim, o humor tem papel decisivo em ampliar o espectro de interesse pela obra, ao torná-la mais desejável para o consumo em família. Ao considerar estar prerrogativa, com a possibilidade do suburbanismo fantástico em trabalhar com elementos semânticos de gêneros historicamente estabelecidos como aventura, ação, melodrama, ficção científica, fantasia, entende-se o potencial mercadológico dele sobre esses outros gêneros. Afinal, se um filme de horror pode afastar grande parte da audiência, uma abordagem mais bem humorada de seus elementos como Gremlins pode agradar tanto os espectadores ávidos por narrativas monstruosas como grupos familiares mais heterogêneos.

Essa características do subgênero não só aumentou as possibilidades criativas dos roteiristas, como também permitiu que se produzissem obras que buscassem embarcar no sucesso de filmes de outros gêneros com audiências mais especializadas. McFadzean (2019) cita, por exemplo, como Esqueceram de Mim era uma versão infantil de Duro de Matar (Die Hard, John McTiernan, 1988) - um filme rated $R^{8}$. Para efeitos de comparação, enquanto o filme estrelado por Bruce Willis foi um sucesso de bilheteria arrecadando 140 milhões de dólares pelo mundo, o filme que estourou a carreira de Macaulay Culkin fez 477 milhões de dólares, sendo, em seu tempo, a terceira maior bilheteria da história. O recorde da época, não surpreendentemente, era de E.T. - O Extraterrestre, o precursor do suburbanismo fantástico.

Avançando um pouco mais à discussão, é importante considerarmos, para além do número cru da bilheteria, o impacto que o subgênero tinha em suas audiências. Novamente

\footnotetext{
${ }^{8}$ Classificação dada pela Motion Picture Association para filmes que só podem ser assistidos por menores de 17 anos que estiverem juntos com os pais ou responsáveis legais.
} 
proponho usar E.T. - O Extraterrestre como exemplo de caso. Não é insensato pensar que, por trás do sucesso de bilheteria da obra, estava sua capacidade de falar diretamente com toda uma classe média suburbana cujos filhos finalmente podiam ir ao cinema para assistir obras que se referissem a sua subjetividade e sensibilidade (MCFADZEAN, 2019). Esses jovens finalmente poderiam assistir filmes com protagonistas de sua idade e morando em lugares parecidos com suas vizinhanças, com o mesmo problemas, aflições e sonhos. Além disso, seus pais, filhos do baby boom do pós guerra, podiam compartilhar com os filhos a experiência de sua infância no subúrbio e de referências semânticas (ficção científica, fantasia e horror) de obras cinematográficas de sua época.

Lembramos que, nos anos 1950, o cinema "jovem” de fantasia era marcado por obras de ficção científica e horror voltadas para grupos de adolescentes em drive-ins (JONES et al., 2011; GEORGE, 2013). Falamos de obras como Guerra dos Mundos (War of the Worlds, Byron Haskin, 1953), Invasores de Marte (Invaders from Mars, William Menzies, 1953), A Ameaça Veio do Espaço (It Came from Outer Space, Jack Arnold, 1953), O Mundo em Perigo (Them!, Gordon Douglas, 1954) e Vampiros de Almas (Invasion of the Body Snatchers, Don Siegel, 1956). Nesse sentido, o suburbanismo fantástico, ao mirar em públicos mais jovens, sendo bem humorado e leve, mas com atualizações de referências semânticas da infância de platéias mais velhas, conseguiu ampliar de forma contundente suas audiências e fomentar o subgênero como o conhecemos hoje.

Como adiantamos, no entanto, esta é apenas a face mais evidente pela qual o humor se justifica dentro das narrativas do suburbanismo fantástico. Nos próximos tópicos, iremos nos debruçar em algumas outras questões vinculadas diretamente a construção sintática do subgênero e que trazem imbricamentos como o recorte de classes em suas produções.

\section{A comicidade e o distanciamento emocional do melodrama}

Como Olson (2001) e McFadzean (2019) bem pontuam, o melodrama do amadurecimento masculino são parte recorrente da sintaxe do suburbanismo fantástico. De tal forma, faz-se importante investigar como o humor opera diante dessas estruturas sintáticas melodramáticas, uma vez que elas se posicionam em espectros opostos: enquanto o humor exige certo distanciamento emocional, o melodrama tende a exigir a proximidade afetiva e sentimental entre o espectador e as personagens.

Antes de mais nada é importante distanciar o melodrama do amadurecimento do suburbanismo fantástico com o dos coming of age dramas - definição genérica ampla o bastante para incorporar obras com temáticas tão díspares como Lagoa Azul (The Blue Lagoon, 
Randal Kleiser, 1980), Eu, Christiane F. - Drogada Prostituída (Christiane F., Uli Edel, 1981), A Sociedade dos Poetas Mortos (Dead Poets Society, Peter Weir, 1989) e O Senhor das Moscas (Lord of the Flies, Harry Hook, 1990). Enquanto, nos coming of age dramas, o amadurecimento está vinculado ao aprendizado de diversos aspectos da sociedade: a sexualidade, a reprodução de um estilo de vida "saudável", o aprendizado cultural ou mesmo a violência, no caso do suburbanismo fantástico, ele está mais ligado ao despertar heróico (emprestado do gênero de fantasia) a partir da provação do protagonista em demostrar sua robusteza e autosuficiência.

Ashley Carranza (in WETMORE, 2018) em seus estudos sobre Stranger Things (Irmãos Duffer, Netflix, 2016-), utiliza-se da teoria da autodeterminação (Self Determination Theory) da psicologia para explicar de forma mais profunda como se dá "processo de amadurecimento" no suburbanismo fantástico. Em suas palavras

\footnotetext{
[a] teoria da autodeterminação descreve o método psicológico pelo qual uma pessoa se torna dependente de si mesma e permite que os impulsos internos se concentrem no processo de tomada de decisão (...) Ela se aplica diretamente e explica o rápido amadurecimento dos personagens, (Carranza apud Wetmore, 2018, p.15). (tradução do autor P.L. $)^{9}$
}

A pesquisadora aponta que a teoria da autodeterminação sublinha três necessidades psicológicas básicas que todo o ser humano tem: competência (ser eficiente em seu próprio ambiente), autonomia (tomar o controle da própria vida) e afinidade (criar relações afetivas com outros). Como McFadzean (2017; 2019) faz questão de ressaltar, no subgênero aqui estudado, o amadurecimento do protagonista vem junto à execução de atos heróicos e físicos, de coragem, esperteza e destreza. Exemplos consagrados são do menino Kevin criando armadilhas em sua casa em Esqueceram de Mim, dos jovens de Os Goonies fugindo de um antigo navio pirata ou Elliot fugindo das autoridades em sua bicicleta em E.T. - $O$ Extraterrestre. Ou seja, os melodramas familiares desses personagens não são resolvidos por conversas, exposições de sentimentos, manifestações artísticas, ou processos de luto, mas pela aventura e pelo confronto com o fantástico. Algo que é particularmente marcante em um subgênero onde os protagonistas tem problemas facilmente relacionáveis como:

(...) medo e ansiedade a partir de tramas sociais como amizade, família, escola, bullying e relacionamentos: a sensação de deslocamento a partir de uma mudança

\footnotetext{
${ }^{9}$ No original: "Self Determination Theory describes the psychological method in which a person becomes reliant upon themselves and allows internal drives to focus on the decision making process. (...) applies directly and explains the rapid maturation within the characters as well as their willingness to form strong bonds, creating the CCP."
} 
(Garotos Perdidos, Abracadabra, Jumanji); o processo de divórcio e separação (E.T. - O Extraterrestre, Zathura); a morte de um parente (Os Heróis não tem Idade; Jumanji); a chegada de um vizinho novo (Uma Noite Alucinante); alienação da família (O Vôo do Navegador; Jumanji; Pequenos Guerreiros); o desafio de fazer e manter novos amigos (Garotos Perdidos; Abracadabra); a ameaça de bullies (Viagem ao Mundo dos Sonhos; De Volta para o Futuro; Abracadabra; Jumanji); sentimentos de atração e desejo (Os Goonies; Uma Noite Alucinante; Mulher Nota 1000; Abracadabra). (McFadzean, 2019, p.52). (tradução do autor P.L.) ${ }^{10}$

O humor, neste caso, parece operar de forma a permitir que o filme possa se utilizar do melodrama do amadurecimento, sem se confundir com um coming of age drama. Além disso, o distanciamento emocional do humor auxilia na suspensão da descrença, facilitando que aceitemos o amadurecimento do protagonista a partir das cenas de ação, aventura e fantasia. Assim, aceitamos o amadurecimento de Kevin, o protagonista de Esqueceram de Mim ao impedir que bandidos invadam sua casa, sem que ele tenha sequer resolvido os problemas afetivos com sua família. Isso, é claro, acaba fazendo com que o processo de maturação ocorra de forma fantástica e desprovida de realidade, algo particularmente chamativo em um gênero androcêntrico e branco, no qual o protagonista ao invés de lidar com o peso de seus dramas emocionais, é retratado como alguém que resolve seus problemas a partir de "boas sacadas", "insights" ou provas de coragem. Usando outro exemplo, é notável que Elliot reconstrua os laços com sua mãe ao entrar em um missão conjunta de salvar o alienígena, e não a partir de um diálogo sobre o divórcio com seu pai.

É impossível não trabalhar tais características dentro da conjuntura na qual muitos desses filmes da década de 1980 se encontravam: a da Era Reagan e o chamado entretenimento reaganista. Andrw Britton (2009) vai definir essa conceituação como “obras que buscavam o equilíbrio aceitável entre prazer (no sentido de ser uma antítese para os problemas mundanos) e a sensação de que - por ser prazer - não guardava relação séria com a vida real" ${ }^{11}$ (p. 101 tradução do autor P.L.). Walters (2011) fala sobre um estado de ansiedade perpétua (e institucionalizada) do espectador causada pela dicotomia entre o prazer imediato de escapar da realidade ao assistir a obra e a imediata sensação de que era "apenas um filme" ao seu final. Ou seja, percebe-se um papel estratégico do humor em facilitar a suspensão da descrença nesses

\footnotetext{
${ }^{10}$ No original: "fear and anxiety over social dramas of friendship, family, school, bullying and love: the sense of dislocation from moving house (The Lost Boys, Hocus Pocus, Jumanji); the process of coming to terms with parental divorce or separation (E.T., Zathura); the death of a parent (Cloak and Dagger, Jumanji); the arrival of a new neighbour (Fright Night); alienation from the family (Flight of the Navigator, Jumanji, Small Soldiers); the challenge of making and keeping new friends (The Lost Boys, Hocus Pocus, The Hole); the threat of bullies (Explorers, Back to the Future, Hocus Pocus, Jumanji); and the strange new feelings of attraction and desire (The Goonies, Fright Night, Weird Science, Hocus Pocus)."

${ }^{11}$ No original: "an acceptable balance between a yield of pleasure-a sense that one's escape has been valuableand a feeling that, because it is escape, the experience bears no serious relation to the real business of life."
} 
filmes, permitindo que a ação seja concluída sem excessivos desdobramentos melodramáticos, facilitando a comercialização da própria obra. Afinal, por mais que ambas as obras trabalhem com a narrativa do divórcio e suas consequências, as multidões que iam assistir E.T. - O Extraterrestre, não o iam com intuito de ver uma versão de Kramer vs Kramer (Robert Benton, 1979) com alienígenas.

Um exemplo bastante didático de como essa "necessidade do humor" também opera a nível mercadológico (algo importante quando falamos do meio cinematográfico) se deu em $D e$ Volta para o Futuro, quando, depois de seis semanas de filmagem, o ator Eric Stoltz foi substituído por Michael J. Fox como protagonista da obra. Além de ser considerado uma figura difícil no set, o diretor Robert Zemeckis dizia que Stoltz não conseguia entregar o nível de comédia necessário para o filme funcionar ${ }^{12}$. Segundo Zemeckis, Stoltz encarava a história do garoto preso no passado como um grande drama existencial, dando mais foco aos aspectos melodramáticos do que na potencial comédia da situação. $\mathrm{O}$ drama, por sua vez, iria colocar um grau de exigência do espectador em ser convencido pela premissa "ridícula" da viagem do tempo. Segundo Zemeckis, para comprarmos a trama de viagem do tempo do filme, precisaríamos de um certo distanciamento emocional do herói a partir do humor. E como sintetizou Bergson (2004): “o riso não tem maior inimigo que a emoção" (p.12).

Então, se semanticamente cada uma das irrupções do fantástico traz apreensões e trata de ansiedades específicas vinculadas ao processo de amadurecimento, isto traz um custo emocional no melodrama do protagonista. Afinal, é difícil se identificar com um processo de amadurecimento advindo de uma viagem no tempo ou do salvamento de um alienígena. $\mathrm{O}$ processo então se torna meramente especulativo - "o que faríamos se estivéssemos em igual situação". O humor permite que o melodrama cotidiano nunca se coloque a frente da aventura, garantindo assim, a própria fidelidade do filme ao seu subgênero.

\section{O aspecto cômico da desidentificação do Outro}

A fantasia no suburbanismo fantástico pode ter diversos alinhamentos para com o protagonista: ela pode ameaçá-lo (Gremlins), necessitar de sua proteção (E.T. - O Extraterrestre) ou lhe dar poderes (De Volta paro Futuro). Independente do alinhamento, na maioria dos filmes do subgênero vai ser esse elemento fantástico o maior responsável pelos momentos bem humorados. Isso porque essa figura do Outro representa conceitos, performatividades e/ou experiências que não são compreendidas pelo protagonista (pois são da

\footnotetext{
${ }^{12} \mathrm{https} / / /$ screenrant.com/back-future-original-marty-fired-eric-stoltz-why/ Acesso em 30/12/2020.
} 
ordem do "extra-ordinário"). A comédia nesse caso surge da tentativa de normatização (o emprego de regras sociais, geralmente heteronormativas, patriarcais e brancas) ou punição (enfrentamento físico, vingança) daquela figura tida como dirsruptiva.

Em De Volta para o Futuro, por exemplo, diversas sequências de humor são construídas a partir da premissa de Marty ter que "educar" seus pais na juventude. Isso ocorre em cenas nas quais Marty tenta controlar a atração sexual de sua mãe por ele, como, também, na tentativa de ensinar "valores masculinos" para seu pai: ou seja, enfrentar fisicamente seus problemas e proteger sua amada, se alinhando ao ideal de masculinidade da era Reagan (DWYER, 2005). Outro filme que segue a mesma máxima é Um Hóspede do Barulho (Harry and the Hendersons, William Dear, 1987) no qual o humor está justamente na tentativa de uma família domesticar um "pé grande" (Figura 3) - ensinando o que este "precisa" para conviver naquela sociedade.

Na cena apresentada na Figura 3, o Pé-Grande é cuidado pela família Henderson, cortando o cabelo e fazendo a unha - ritos "necessários” para que ele se encaixe na sociedade.

Figura 3 - Cena de Um Hóspede do Barulho

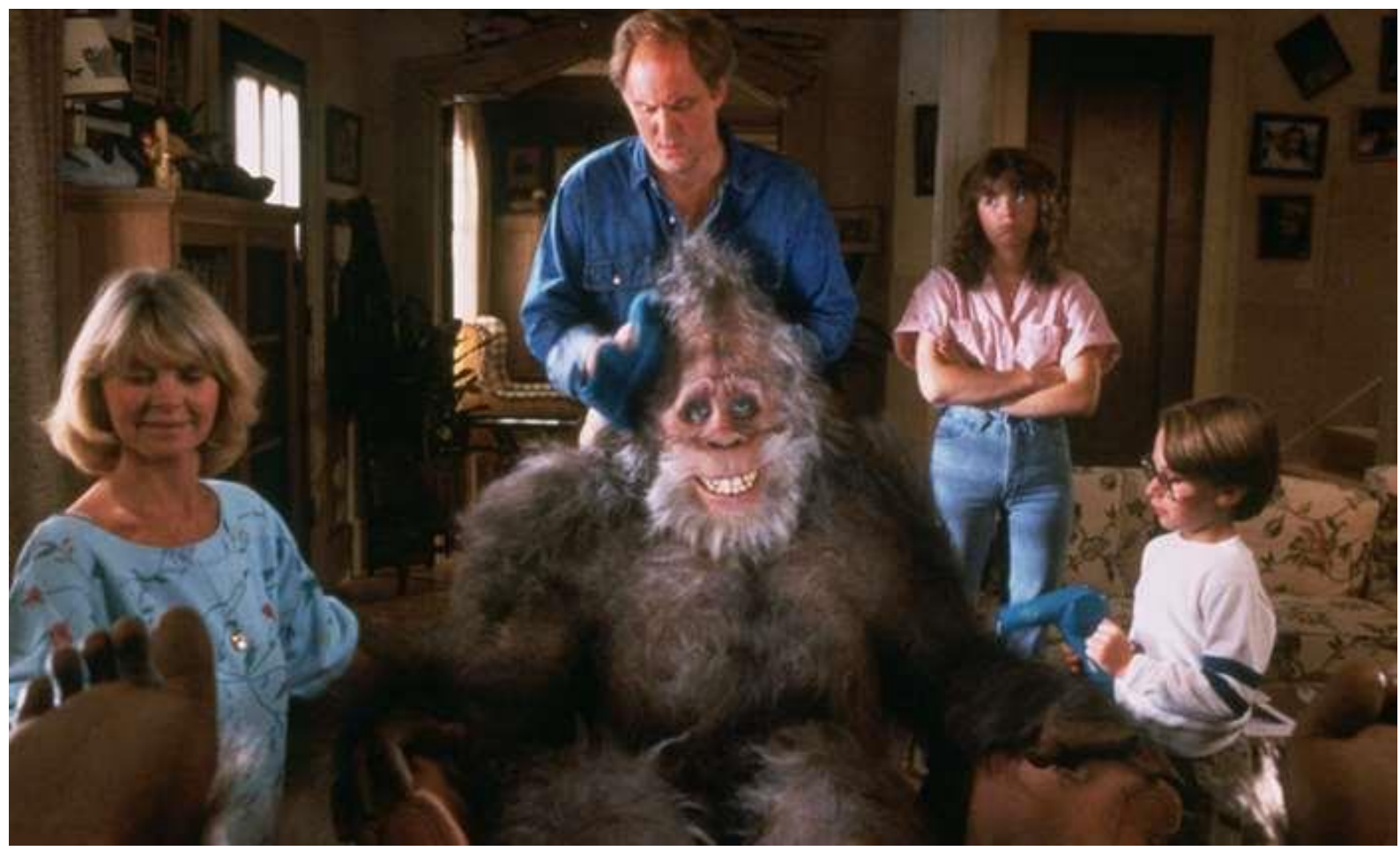

Fonte: Frame do filme

Indo mais além, Wojcik-Andrws (2000) e Stephen Prince (2007) se debruçam sobre uma cena particular de E.T. - O Extraterrestre, para demonstrar como essas cenas bem humoradas acabam por camuflar narrativas de assimilação. No caso, falamos da cena em que o E.T. é vestido como mulher (Figura 4) e recebe o que ele entende como uma reação negativa por parte 
do alienígena. Isto faz com que Elliott conclua que ele seja "macho" - ou seja, impondo seus valores de heteronormatividade à uma outra espécie. Um outro momento citado por Prince (ibidem) talvez seja ainda mais revelador sobre as dinâmicas por trás processo de assimilação: quando a pequena Gertie ensina ao alienígena a falar as letras do alfabeto. Tal artimanha de socialização, inclusive, é muito similar àquelas presentes em Um Hóspede do Barulho e outros filmes do subgênero como Short Circuit (John Badham, 1986), Deu a Louca nos Monstros (Monster Squad, Fred Dekker, 1987) e Comando Suburbano (Suburban Commando, Burt Kennedy, 1991),

Figura 4 - Cena de E.T. - O Extraterrestre: O alienígena "vestido como mulher"

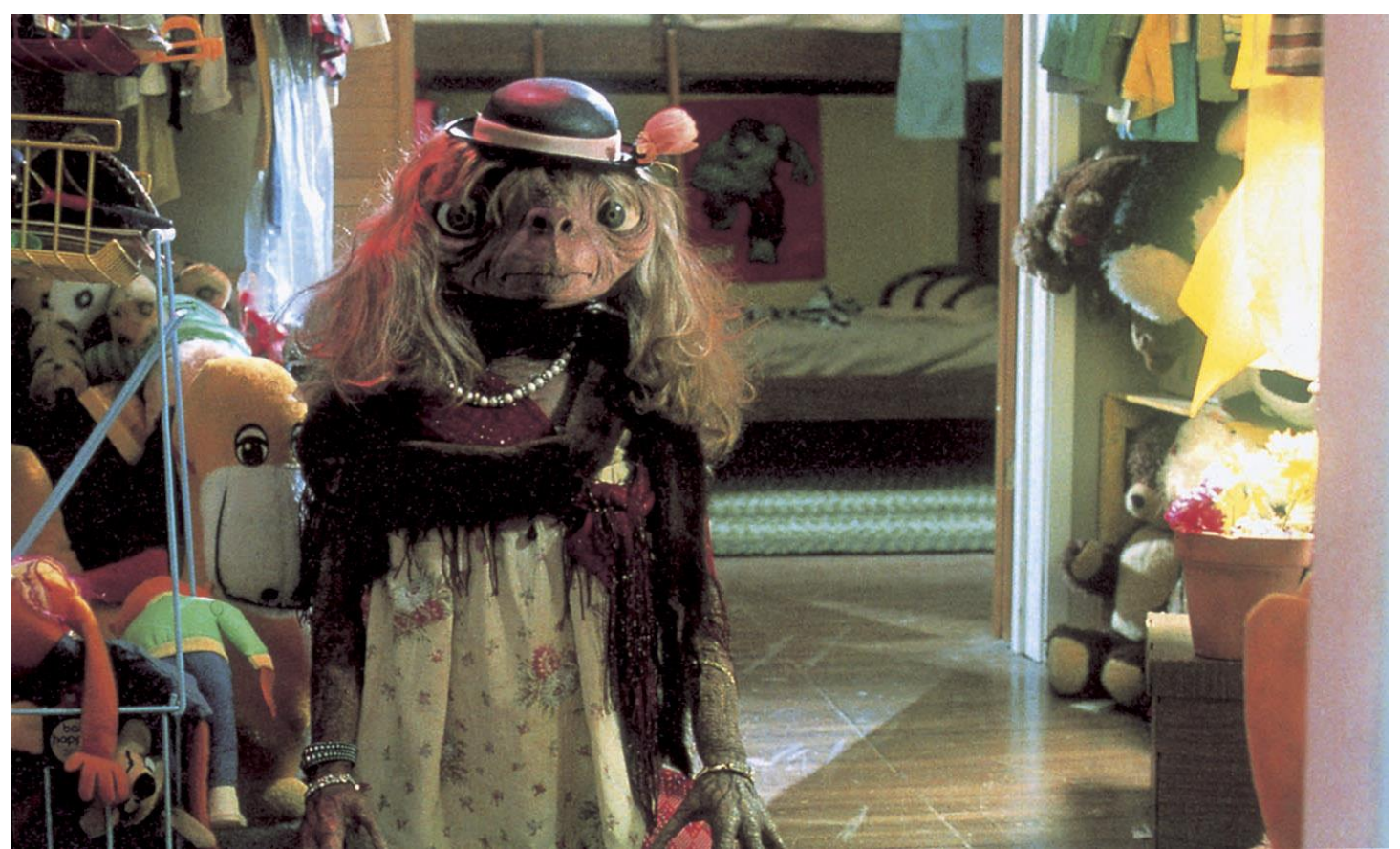

Fonte: Frame do filme.

Essas narrativas de assimilação logo evocam a noção de Bergson (2004) do riso como defesa social contra aqueles que se recusam ou não conseguem se adaptar às normas da sociedade. Ou seja, trazendo um caráter "punitivo" da risada do espectador àqueles que “ousam" ser desviantes das condutas sociais. Isto, por sua vez, normatiza e normaliza nossa própria conduta como parte (ou como interessado em fazer parte) daquele grupo social. Se rimos do E.T. vestido "como mulher", é porque concordamos com a visão social de Elliot (um garoto de classe média branco) de que ele não deveria se vestir assim. Afinal, rir daqueles que não se encaixam nas regras ou ordem moral de seu grupo traz um certo afago da nossa própria posição social. 
Nesse sentido, é particularmente interessante pontuarmos como tanto a comédia quanto a fantasia, partes presentes no subgênero, se encontram no papel de confrontar as expectativas do real. Como estabelece David Roas (2001), o fantástico provoca a incerteza do real frente ao impossível, desestabilizando a lógica racional que garantiria a segurança e a tranquilidade do espectador. Ainda mais simbólico é que dentro dessas narrativas do suburbanismo fantástico, a jornada do protagonista se conclua com a resolução da disrupção (causada pelo fantástico) e pela retomada do status quo, permitindo um retorno "da normalidade" onde as regras do real (e do subúrbio) são respeitadas.

Seguindo essa perspectiva, é crucial sublinhar que, nos filmes citados, o humor está na dificuldade do protagonista em ensinar suas práticas sociais e não em sua dificuldade de aprender algo com elas. Tudo que é tido como aprendizado nesse filme, vem de lições autocentradas (lembrando da Teoria da Auto-Determinação) da importância da família e do seu papel, como homem branco, de preservá-la frente aos ataques de agentes externos. Tais levantamentos tornam bastante claro como o Outro nessas obras não gera nenhum tipo de ameaça à posição privilegiada do protagonista, que não se sente obrigado a rever seus privilégios e nem aprender com aqueles outros corpos. É partindo desse preceito que Prince (2007, p.69) chama a atenção para como "E.T. representa uma imagem domesticada e não ameaçadora do Outro (qualquer coisa que exista além do estilo de vida suburbano branco e de classe média)". Ele cita Robin Wood (apud PRINCE, 2007, p.69) para contextualizar essa discussão em "uma nação fundada na negação do Outro, que depois dos movimentos radicais feministas, (...) da militância negra, (...) e LGBT, produziu uma figura do Outro que todos pudessem amar, abraçar e se emocionar, (...) sem perturbar o "American Way of Life" (epítome máxima da classe média suburbana) (tradução do autor P.L.). ${ }^{13}$

Wojcik-Andrews (2000) apresenta uma leitura marxista de que a figura do Outro nesses filmes é uma commodity com função narrativa vinculada à concretização de certos ritos patriarcais e capitalistas. Ele ressalta como essas commodities (os "Outros") facilitam para o protagonista (que teria elas quase como uma propriedade privada) a aquisição de mais riquezas, seja literal, seja simbólica (o interesse romântico, a compreensão da família, o respeito dos amigos). Assim, o próprio humor, ao desidentificar o Outro, facilitaria a percepção dele como um instrumento que traria ao protagonista aquilo que a sociedade capitalista privilegia:

\footnotetext{
${ }^{13}$ No original: "[A] nation that was founded on the denial of Otherness now-after radical feminism, after gay liberation, after black militancy — complacently produces a film in which Otherness is something we can all love and cuddle and cry over, without unduly disturbing the nuclear family and the American Way of Life"
} 
heteronormatividade, relações monogâmicas, propriedade privada, status de classe, sucesso, riquezas materiais, etc.

Talvez a obra mais representativa dessa lógica no suburbanismo fantástico seja a comédia Meus Vizinhos são um Terror (The burbs, Joe Dante, 1989). O maniqueísmo e a visão superficial de mundo estão presentes desde o pôster (Figura 5), separando o Outro da classe média suburbana, o "Nós" (como perspectiva hegemônica). O uso de elementos semânticos típicos do horror para caracterizar os vizinhos tidos como "estranhos" poderia, inclusive, ser apenas um exagero cômico devido ao principal tema do filme: a paranoia do homem suburbano estadunidense com esse Outro (pessoas que não se encaixam no modelo de família nuclear branca heteronormativa).

A Figura 5 apresenta o pôster do filme Meus Vizinhos são um Terror, que separa, do lado esquerdo, o Outro, com símbolos sinistros como caveiras, motosserra e uma casa malassombrada, e, do lado direito, os moradores "tradicionais do subúrbio".

Figura 5 - Pôster de Meus Vizinhos são um Terror

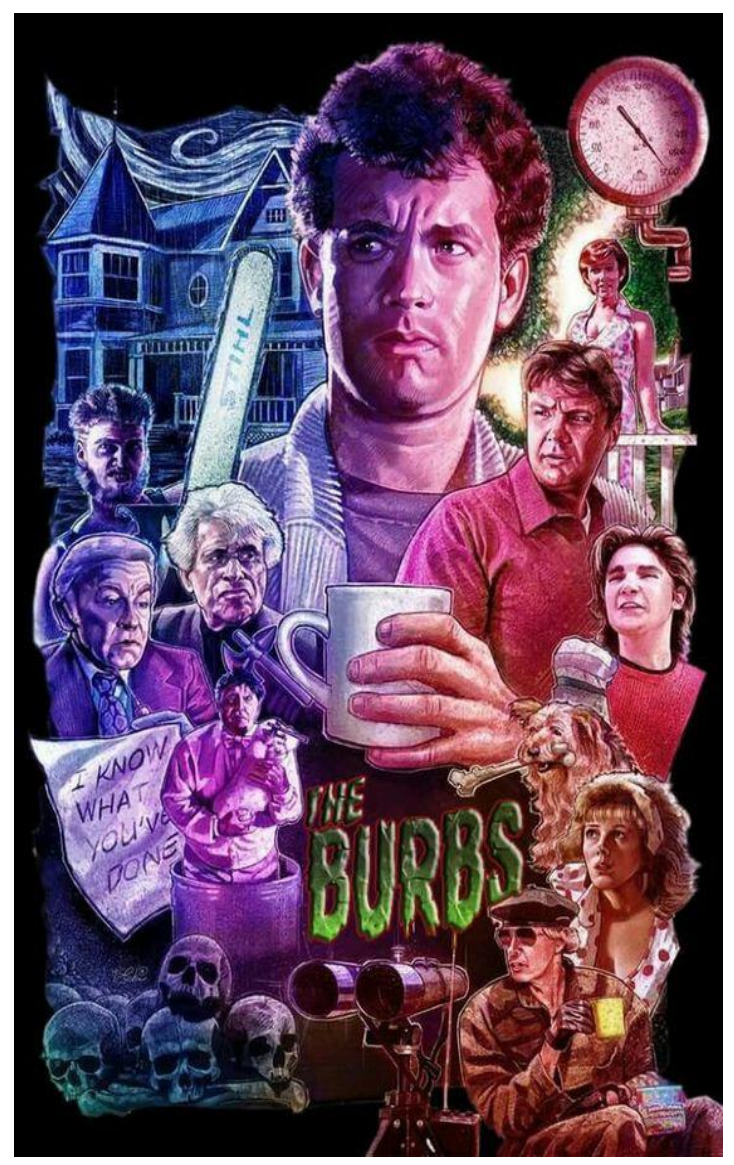

Fonte: Collectors.com 
A narrativa da obra, inclusive, nos leva a acreditar que o amadurecimento dos protagonistas se dará a partir compreensão da necessidade de tolerância ao diferente. Afinal, não é porque seus vizinhos parecem "estranhos", que eles são assassinos monstruosos. No entanto, a última sequência do filme implode essa construção. Nela, a paranoia não fundamentada do trio de protagonistas, que comete uma série de crimes (do vandalismo até a invasão de propriedade) é o que salva o subúrbio de uma família de psicopatas. O humor, novamente, passa a reafirmar os valores desse homem branco de classe média - afinal, ri-se do fato de que "eles estavam certos o tempo todo". O Outro, nesse sentido, se torna a commodity pelo qual os protagonistas alcançam o reconhecimento de seus iguais (vizinhança suburbana), que ficam agradecidos por todos os atos (ilegais) perpretados por eles.

\section{Algumas considerações finais}

Estabelecendo, desde o início, o histórico e ordenamento de classes em que consiste o subúrbio estadounidense e suas representações, o presente trabalho se pautou em mostrar como o humor pode ser usado para a manutenção de certas perspectivas sociais. Estratégico para um subgênero tão popular como o suburbanismo fantástico. A comédia, para além de sua funcionalidade mercadológica de aumentar a amplitude de sua audiência, permitindo que os filmes sejam assistidos por toda família, apresenta ao menos duas funções sintáticas. São elas:1) Atenuar o caráter emocional do melodrama do herói, evitando maiores aprofundamentos dentro de seu processo de amadurecimento; 2) Desidentificar a figura do Outro, para que ele sirva de instrumento narrativo (ou commodity) no processo de maturação do protagonista.

Nesse sentido, apesar de trabalharem com elementos semânticos do fantástico, os gêneros de fantasia e o suburbanismo fantástico parecem destoar em alguns de seus fundamentos de ordem moral. Se David Roas (2001) diz que o fantástico (e, consequentemente, a fantasia) é um gênero profundamente subversivo, ao confrontar tematicamente e linguisticamente a realidade estabelecida, o próprio componente sintático do suburbanismo fantástico parece apresentar uma natureza contrária que coloca o protagonista para confrontar qualquer possibilidade de perturbação do real.

Ressaltamos que seria equivocado traçar qualquer consideração mais consolidada sobre o subgênero em si, uma vez que fazê-lo exigiria a análise de um escopo muito maior. No entanto, o presente trabalho parece sugerir que o humor dentro do suburbanismo fantástico é, ao menos em alguns casos, instrumental para a manutenção de um olhar condescendente com a classe média suburbana, reafirmando alguns de seus privilégios e se opondo à perspectiva crítica feita pelo suburbanismo gótico (e se aproximando muito mais ao olhar das sitcoms de 
subúrbio). No suburbanismo fantástico parece que rimos mais da dificuldade de se interagir com o Outro do que nos preocupamos em reavaliar nossas próprias condutas.

Enfatizamos, por fim, que o presente artigo não tem a intenção de estabelecer máximas condenatórias ao subgênero, ao taxá-lo de conservador ou escapista. Como toda obra artística, ela é indissociável do período e ambiente em que foi realizada. No caso do suburbanismo fantástico, na Hollywood em meio aos anos Reagan, uma década marcada por um discurso nostálgico, suburbanista e ufanista (TROY, 2005; EHRMAN, 2005). Hoje, filmes como $A$ Gente se vê Ontem (See You Yesterday, Stefon Bristol, 2019) e Vampiros x O Bronx (Vampires $x$ The Bronx, Osmany Rodriguez, 2020) começam a trazer perspectivas completamente distintas para o subgênero - empregando o humor de maneira contestadora e de forma a ressignificar o papel do Outro na narrativa.

Por isto, encerramos o presente artigo sublinhando a importância da continuação dos estudos sobre suburbanismo fantástico, que, ao contrário de seus "(sub)gêneros irmãos”, ainda tem uma produção acadêmica bastante recente e diminuta, carecendo de mais estudos para serem incorporados ao seu corpus analítico e que o amplie para além dos estudos audiovisuais, encontrando seus desdobramentos na literatura, nas graphic novels, nos video-games, etc.

\section{Referências}

BERGSON, Henri. O riso. Rio de Janeiro: Martins Fontes, 2004.

BRITTON, Andrew. Britton on Film: The Complete Film Criticism of Andrew Britton. Detroit: Wayne State University Press, EUA, 2009

COONTZ, Stephanie. The Way We Never Were: American Families and the Nostalgia Trap. New York: Basic Books, 2000

DWYER, Michael. Back to the fifties. Nostalgia, Hollywood film, and popular music of the seventies and eighties. New York: Oxford University Press, 2015.

EHRMAN, John. The eighties: American in the Age of Reagan. New Haven: Yale University Press, 2005.

FORREST, David; HARPER, Graeme; RAYNER, Jonathan (eds.). Filmurbia: screening the suburbs. London: Palgrave Macmillan, 2017.

GEORGE, Suzan. Gendering science fiction films: invaders from the suburbs. New York: Palgrave Macmillan, 2013.

HANLON, Bernadette. Once the American dream: inner-ring suburbs of the metropolitan United States. Philadelphia, Pennsylvania: Temple University Press, 2009.

JONES, Darryl; McCARTHY, Elizabeth; MURPHY, Bernice (Eds.). It came from the 1950s!. London: Palgrave Macmillan, 2011. 
JURCA, Catherine. White Diaspora. The Suburb and the Twentieth-Century American Novel. New Jersey: Princeton University Press, 2001

McFADZEAN, Angus. The suburban fantastic: a semantic and syntactic grouping in contemporary Hollywood cinema. Science Fiction Film and Television, Volume 10, No 1 Liverpool University, Uk., pp. 1-25 2017

McFADZEAN, Angus. Suburban fantastic cinema: growing up in the late twentieth century. New York: Wallflower Press, Columbia University, 2019

MURPHY, Bernice. The suburban gothic in American popular culture. Basingstoke: Palgrave Macmillan, 2009

OLSON, Lars. Great Expectations: The Role of Myth in 1980s Films with Child Heroes. Blacksburg: Viginia Polytechic Institute, 2011

PRINCE, Stephen. American cinema of the 1980s. New Brunswick, NJ: Rutgers University Press, 2007

ROAS, David (ed.) Teorias de lo fantastico. Madrid: Arco Libros, 2001.

ROWLEY, Stephen. Movie towns and sitcom suburbs: building Hollywood's ideal communities. New York: Palgrave Macmillan, 2015

SANTOS, Roberto Elísio dos. Reflexões teóricas sobre o humor e o riso na arte e nas mídias massivas. In: SANTOS, Roberto Elísio dos; ROSSETI, Regina (Orgs.). Humor e riso nas culturas midiáticas: variações e permanências. São Paulo: Paulinas, 2012.

TAYLOR, Ella. Prime Time Families: Television Culture in Post War America. Berkeley: University California Press. 1989

TOLSTOY, Leon. Anna Karênina. Rio de Janeiro: Itatiaia, 2007

TROY, Gilles. Morning in America: how Ronald Reagan invented the 1980s. Princeton, NJ: Princeton University Press, 2005.

WALTERS, James. Fantasy Film: A Critical Introduction. Berg, New York. 2011

WETMORE JR., Kevin. (Ed.) Uncovering Stranger Things: essays on eighties nostalgia, cynicism and innocence in the series. Jefferson, North Carolina: McFarland Company, 2018.

WOJCIK-ANDREWS, Ian. Children's films: history, ideology, pedagogy, theory. Children's Literature and Culture. Vol. 12. Garland Library of the Humanities. Texas, 2000.

WOOD, Robin. Hollywood from Vietnam to Reagan... and beyond. New York: Columbia University Press, 2003.

WOOD, Robin. Papering the cracs: fantasy and ideology in the Reagan Era. Movies and Mass Culture. New Brunswick: Rutgers University Press, 1996.

Recebido em: 04/02/2021 Aceito para publicação em: 09/04/2021 